OPEN ACCESS

Edited by:

Peiyuan Yin,

Dalian Medical University, China

Reviewed by:

John Reyes Ussher,

University of Alberta, Canada

Neil G. Docherty,

University College Dublin, Ireland

*Correspondence:

Johan W. E. Jocken

j.jocken@maastrichtuniversity.nl

${ }^{\dagger}$ These authors share last authorship

Specialty section:

This article was submitted to

Gut Endocrinology,

a section of the journal

Frontiers in Endocrinology

Received: 28 January 2021

Accepted: 25 May 2021

Published: 17 June 2021

Citation:

González Hernández MA, Blaak EE,

Hoebers NTH, Essers YPG,

Canfora EE and Jocken JWE (2021)

Acetate Does Not Affect

Palmitate Oxidation and AMPK

Phosphorylation in Human

Primary Skeletal Muscle Cells.

Front. Endocrinol. 12:659928.

doi: 10.3389/fendo.2021.659928

\section{Acetate Does Not Affect Palmitate Oxidation and AMPK Phosphorylation in Human Primary Skeletal Muscle Cells}

\author{
Manuel A. González Hernández, Ellen E. Blaak, Nicole T. H. Hoebers, Yvonne P. G. Essers, \\ Emanuel E. Canfora ${ }^{\dagger}$ and Johan W. E. Jocken ${ }^{*+}$
}

Department of Human Biology, School of Nutrition and Translational Research in Metabolism (NUTRIM), Maastricht University, Maastricht, Netherlands

Our recent in vivo human studies showed that colonic administration of sodium acetate (SA) resulted in increased circulating acetate levels, which was accompanied by increments in whole-body fat oxidation in overweight-obese men. Since skeletal muscle has a major role in whole-body fat oxidation, we aimed to investigate effects of SA on fat oxidation and underlying mechanisms in human primary skeletal muscle cells (HSkMC). We investigated the dose (0-5 mmol/L) and time (1, 4, 20, and $24 \mathrm{~h})$ effect of SA on complete and incomplete endogenous and exogenous oxidation of ${ }^{14} \mathrm{C}$-labeled palmitate in HSKMC derived from a lean insulin sensitive male donor. Both physiological ( 0.1 and $0.25 \mathrm{mmol} / \mathrm{L})$ and supraphysiological $(0.5,1$ and $5 \mathrm{mmol} / \mathrm{L})$ concentrations of SA neither increased endogenous nor exogenous fat oxidation over time in HSkMC. In addition, no effect of SA was observed on Thr ${ }^{172}$-AMPK $\alpha$ phosphorylation. In conclusion, our previously observed in vivo effects of SA on whole-body fat oxidation in men may not be explained via direct effects on HSkMC fat oxidation. Nevertheless, SA-mediated effects on whole-body fat oxidation may be triggered by other mechanisms including gut-derived hormones or may occur in other metabolically active tissues.

Keywords: gut metabolite, acetate, fat oxidation, insulin sensitivity (IS), metabolic health

\section{INTRODUCTION}

In the last decades obesity has reached pandemic proportions worldwide (1), indicating the necessity to take action and prevent the development of obesity-related comorbidities. Obesity is characterized by an imbalance in energy intake and expenditure, with the excess energy stored in adipose tissue depots. It is increasingly clear that not adipose mass per se but rather adipose tissue dysfunction plays a central role in the observed metabolic derangements (1). A limited buffering capacity may result in systemic lipid overflow and an increased lipid supply to non-adipose tissues. Consequently, this may, together with an impaired oxidative capacity cause ectopic fat deposition in important metabolically active tissues (i.e. skeletal muscle, liver), which may link to the development of insulin resistance (2). 
Of note, evidence is accumulating that energy and substrate metabolism and insulin sensitivity may be modulated by gut microbially derived metabolites, thus bringing attention to the cross-talk between gut-microbiota-derived metabolites and host metabolic health $(3,4)$. In the colon, fermentation of indigestible food compounds by the resident microbiota plays a pivotal role in the production of short-chain fatty acids (SCFA), including acetate, propionate, and butyrate $(3,5,6)$. Of these SCFA, acetate is the most abundant in the colon and has potential beneficial effects on energy expenditure and substrate metabolism (7). Circulating levels of acetate can reach physiological concentrations that range between 5 up to an average of 450 $\mu \mathrm{mol} / \mathrm{L}$, predominantly after prebiotic consumption $(4,8-15)$. Subsequently, gut-derived acetate seems to have a broad metabolic role, since the SCFA-sensing G protein-coupled receptors (GPR, 41/43) are expressed in various tissues such as the adipose tissue (16), skeletal muscle, liver (17), and pancreatic beta cells $(18,19)$. Circulating acetate has been shown to have antilipolytic effects in adipose tissue in in vitro (20-22), animal $(20,23)$, and human studies (24-27), thus potentially reducing lipid overflow, improving lipid buffering capacity and impacting peripheral insulin sensitivity. Other potential metabolic effects may include the induction of satiety mediated via the stimulation of glucagon-like peptide 1 (GLP-1) and peptide YY (PYY) secretion $(28,29)$.

In addition to satiety, SCFA effects on intestinal gluconeogenesis and increased skeletal muscle fat oxidation have been observed at least in rodents (3). Furthermore, an in vitro study in L6 myotubes showed that acetate acutely (following $2 \mathrm{~min}$ ) increased AMP-activated protein kinase (AMPK) phosphorylation via increased adenosine monophosphate (AMP)/adenosine triphosphate (ATP) ratio (30). Moreover, intragastric injection of acetate in mice showed a rapid increase in muscle AMP/ATP ratio and AMPK phosphorylation (31).

In addition to effects on skeletal muscle metabolism, acetate mediated upregulation of genes involved in fat oxidation (uncoupling protein 2, peroxisome proliferator-activated receptor alpha, and carnitine palmitoyl transferase 1) and increased $A M P K$ phosphorylation in murine liver (32-34).

Although no actual substrate oxidation was measured, these studies suggest that acetate may increase liver and skeletal muscle oxidative capacity in an AMPK-mediated fashion, at least in rodent models. Our recently published human intervention study in overweight/obese normoglycemic men showed that acute distal, not proximal, colonic acetate infusions (180 $\mathrm{mmol} / \mathrm{L}$ ) increased fasting fat oxidation by around $25 \%$, which may be possibly mediated via increased circulating acetate levels (7). Together, these data suggest that the observed in vivo effects on whole-body fat oxidation in overweight/obese humans may be partly mediated via a direct effect of circulating acetate on skeletal muscle fat oxidation. Therefore, we hypothesized that SA (sodium acetate) increases fat oxidation in a time- and dosedependent manner in differentiated human primary muscle cells (HSkMC).

Fat oxidation was investigated by measuring SA effects on both endogenous (intracellular) and exogenous (extracellular)
${ }^{14} \mathrm{C}$-palmitate oxidation. Additionally, from a mechanistic perspective, we investigated SA-mediated effects on AMPK phosphorylation in HSkMC.

\section{MATERIALS AND METHODS}

HSkMC were isolated from rectus abdominal muscle tissue following surgery as described previously from a healthy male donor, insulin sensitive (HOMA-IR $=0.37), 45$ year old with a BMI of $23.5 \mathrm{~kg} / \mathrm{m}^{2}$ (Figure S4, Table S1) (35). Cells were proliferated using Dulbecco's modified eagle medium (DMEM) low glucose (5.5 mmol/L) (\#D6046-500 ml, Sigma-Aldrich) supplemented with $16 \%$ fetal bovine serum (FBS) (Batch BDC11933, Bodinco BV), $0.05 \%$ bovine serum albumin (BSA) (\#A4503-100 g, Sigma-Aldrich), $1 \mu \mathrm{mol} / \mathrm{L}$ dexamethasone (\#D4902-100 mg, Sigma-Aldrich), $0.5 \mathrm{mg} / \mathrm{ml}$ bovine fetuin (\#10505053, Thermo Fisher Scientific), $1 \times$ antibiotic/ antimycotic (\#15240-062, Thermo Fisher Scientific), and 0.01 $\mu \mathrm{g} / \mathrm{ml}$ recombinant human epidermal growth factor (\#PHG0311, Thermo Fisher Scientific). Cells were cultured in differentiation medium containing MEM-Alpha medium/Glutamax (\#32561029, Thermo Fisher Scientific) supplemented with 2\% FBS, 0.5 $\mathrm{mg} / \mathrm{ml}$ bovine fetuin, and $1 \times$ antibiotic/antimycotic. Antibodies against total AMPK $\alpha$, and phosphorylated $T h r^{172}$-AMPK $\alpha$ were purchased from Cell Signaling (\#2603 and \#2535, respectively MA, USA). Secondary antibodies (Goat-anti-Rabbit HRP) were purchased from Vector Labs (\#1000). SA was purchased from Sigma-Aldrich (\#S2889). For fat oxidation assay, we used 4-(2Hydroxyethyl) piperazine-1-ethanesulfonic acid (HEPES, \#H3375, Sigma-Aldrich), L-carnitine hydrochloric acid (carnitine, \#C0283, Sigma-Aldrich), ${ }^{14}$ C-palmitate (\#NEC075H250uC, Perkin Elmer), non-labeled palmitate (\#P0500, Sigma-Aldrich), and perchloric acid (\#244252, Sigma-Aldrich).

\section{Cell Culture}

HSkMC were cultivated in proliferation medium under $5 \% \mathrm{CO}_{2}$ at $37^{\circ} \mathrm{C}$. For differentiation towards functional myotubes, medium was changed to differentiation medium when reaching $80 \%$ confluence, as described above. At day 8-11 of differentiation viable myotubes were used for fat oxidation experiments.

\section{Cytotoxicity Assay}

A fluorometric lactate dehydrogenase (LDH) assay was used for estimating the number of nonviable cells, as marker of cytotoxicity (\#G7890, Promega). Differentiated cells were cultured without (0 mmol/L), or with physiological $(0.1 \mathrm{mmol} / \mathrm{L})$ and supraphysiological ( 1 and $5 \mathrm{mmol} / \mathrm{L}$ ) concentrations of SA during 4 and 24 h (Figure S1). Fluorescence was measured using a Spectramax plate reader (Molecular Devices, CA, USA). Percentage of cytotoxicity was calculated in comparison to Triton X-100 (100\% lysis positive control) with the same incubation times.

\section{Fat Oxidation}

For measurement of in vitro fat oxidation cells were incubated with ${ }^{14} \mathrm{C}$ - labeled palmitate $(250 \mu \mathrm{Ci} / \mathrm{ml}$; PerkinElmer, Boston, 
MA, USA) and non-labeled palmitate. Palmitate was coupled to fatty acid free BSA (7.5\%) together with HEPES (100 mmol/L) and carnitine $(40 \mathrm{mmol} / \mathrm{L})$. The label solution contained ${ }^{14} \mathrm{C}$ labeled palmitate $(1 \mu \mathrm{Ci} / \mathrm{ml}), 100 \mu \mathrm{M}$ non-labeled (cold) palmitate, $0.25 \%$ BSA, $12.5 \mathrm{mM} \mathrm{HEPES}$, and $1 \mathrm{mM} \mathrm{L-}$ Carnitine. After SA incubation, complete $\left({ }^{14} \mathrm{CO}_{2}\right)$ and incomplete ( ${ }^{14} \mathrm{ASM}$, acid soluble metabolites) oxidation products were measured, as previously described (36).

${ }^{14} \mathrm{ASM}$ include acetyl-CoA, acetyl carnitines, ketone bodies, and TCA cycle intermediaries. Briefly, following incubation, medium was transferred to a custom-made Teflon 24-well $\mathrm{CO}_{2}$ trapping plate that was sealed, $70 \%$ perchloric acid was injected (Hamilton syringe, 1705N) through a silicon layer in the lid directly into the media. This moved the $\mathrm{CO}_{2}$ through a tunnel to an adjacent well where it was trapped in $1 \mathrm{~N} \mathrm{NaOH}$. After overnight trapping, complete and incomplete oxidation products were measured by Scintillation counting (using a Tri-Carb 2910 TR liquid scintillation analyzer, Perkin Elmer). For measuring endogenous fat oxidation, cells were pre-incubated for $24 \mathrm{~h}$ with ${ }^{14} \mathrm{C}$ - labeled palmitate $(250 \mu \mathrm{Ci} / \mathrm{ml}$; PerkinElmer, Boston, MA, USA) without carnitine and washed prior to SA incubations.

\section{Western Blotting}

Following incubations without $(0 \mathrm{mmol} / \mathrm{L})$ or with SA $(0.1$ or 0.5 $\mathrm{mmol} / \mathrm{L})$, cells were washed with ice-cold PBS and lysed with RIPA buffer supplemented with protease (\#04693132001, SigmaAldrich) and phosphatase (\#04906845001, Sigma-Aldrich) inhibitors. Samples were vortexed, left on ice $(\sim 10 \mathrm{~min})$ and snap-frozen in liquid nitrogen. Supernatants were subjected to western blot analysis. Briefly, a total of $10 \mu \mathrm{g}$ of protein was loaded on a $4-12 \%$ SDS-PAGE gel using a Criterion XT precast gel (10300 kilodaltons, Bio-Rad) with MOPS buffer (\#161-0788, Biorad). After separation, proteins were transferred using a Criterion blot system (Bio-Rad) in 1xTG buffer (20\% methanol + 0.05\% SDS) onto a $0.45 \mu \mathrm{m}$ nitrocellulose membrane (GE Healthcare, Netherlands), and membranes were blocked using tris-buffered saline (TBS)/3\%BSA/0.1\%Tween-20 [for phosphorylated antibodies and for non-phosphorylated antibodies they were blocked in TBS/5\%non-fat dry milk (NFDM)/0.1\%Tween-20]. Next, the membrane was incubated with primary antibodies (rabbit-anti human p-AMPK diluted 1:1,000 in TBS/3\%BSA/ $0.1 \%$ Tween and rabbit-anti human AMPK in TBS/5\%/NFDM/ 0.1\%Tween-20) (Cell Signaling \#2535 and \#2603, respectively). After overnight incubations at $4^{\circ} \mathrm{C}$, membranes were washed three times with tris-buffered saline tween (TBST) and incubated with HRP-conjugated secondary antibodies for $1 \mathrm{~h}$ (goat-anti-rabbit HRP) diluted $1: 10,000$ in TBS 3\%BSA/0.1\%Tween-20 or in TBS/ $5 \%$ NFDM/0.1\%Tween-20.

Finally, after washing with TBST, last time with TBS, bands were visualized using ECL substrate (Super Signal West Femto, \#34095, Thermo Scientific) according to the protocol supplied by the manufacturer using the Bio-Rad ChemiDoc imaging system (Biorad).

\section{Statistical Analysis}

Values are expressed as mean and standard deviation. Significance was determined using the nonparametric Mann
Whitney U-test when comparing two groups or the KruskalWallis H-test, for multiple comparisons. In case of significant Kruskal-Wallis, Dunn's post hoc test was performed.

Statistics were performed using the GraphPad Prism 5.0a software package (GraphPad Software, San Diego, CA, USA) and a $\mathrm{P}<0.05$ (two-sided $\mathrm{P}$-value) was considered statistically significant.

\section{RESULTS}

\section{Time-Dependent Effect of SA on Exogenous and Endogenous Palmitate Oxidation}

First of all, both acute $(4 \mathrm{~h})$ as well as chronic ( $24 \mathrm{~h})$ incubation with physiological $(0.1 \mathrm{mmol} / \mathrm{L})$ and supraphysiological concentrations ( 1 and $5 \mathrm{mmol} / \mathrm{L}$ ) of SA did not affect LDH activity, indicating no cytotoxic effect of SA in HSkMC (see Figure S1). Secondly, we investigated whether SA has a timedependent effect on complete or incomplete exogenous/ endogenous ${ }^{14} \mathrm{C}$-palmitate oxidation in differentiated HSkMC. Briefly, cells were incubated with a physiological concentration of SA $(0.1 \mathrm{mmol} / \mathrm{L})$ or without $(0 \mathrm{mmol} / \mathrm{L})$ for up to $24 \mathrm{~h}$. As expected, and shown in Figure 1, an increase in fat oxidation was observed over time. However, both complete (Figure 1A) and incomplete (Figure 1B) exogenous fat oxidation were not affected when comparing SA to control treated cells after acute (1-4 h) and chronic (20-24 h) exposure. Next, to investigate the effect of SA on endogenous fat oxidation cells were first preincubated with ${ }^{14} \mathrm{C}$-palmitate for $24 \mathrm{~h}$ and after removal of the label, cells were incubated with SA $(0.1 \mathrm{mmol} / \mathrm{L})$ or without $(0$ $\mathrm{mmol} / \mathrm{L}$ ) for up to $24 \mathrm{~h}$. Although we found a significant increase over time, no differences were observed between SA and control treated cells in complete (Figure 1C) and incomplete (Figure 1D) endogenous fat oxidation at each timepoint.

\section{Dose-Dependent Effect of SA on Exogenous or Endogenous Fat Oxidation}

Subsequently, we investigated the dose-effect of SA on exogenous fat oxidation in differentiated HSkMC. Cells were incubated without $(0 \mathrm{mmol} / \mathrm{L})$, or with physiological $(0.1$, $0.25,0.5 \mathrm{mmol} / \mathrm{L}$ ) and supraphysiological (1 and $5 \mathrm{mmol} / \mathrm{L}$ ) concentrations of SA for up to $20 \mathrm{~h}$. However, as shown in Figure 2, SA did neither increase complete (Figure 2A) nor incomplete (Figure 2B) exogenous fat oxidation as compared to control treated cells.

To investigate dose-dependent effect of SA on endogenous fat oxidation cells were first pre-incubated with ${ }^{14} \mathrm{C}$-palmitate for $24 \mathrm{~h}$ and after removal of the label, cells were treated without $(0$ $\mathrm{mmol} / \mathrm{L})$, or with physiological $(0.1,0.25,0.5 \mathrm{mmol} / \mathrm{L})$ and supraphysiological ( 1 and $5 \mathrm{mmol} / \mathrm{L}$ ) concentrations of SA for up to $20 \mathrm{~h}$. In line with the exogenous oxidation data, we did not observe a dose-dependent increase in complete (Figure 2C) palmitate oxidation as compared to control treated cells. However, we found a significant decrease in the incomplete oxidation (Figure 2D), but only following incubation with the highest dose $(5 \mathrm{mmol} / \mathrm{L})$ of SA $(\mathrm{P}<0.05)$. 


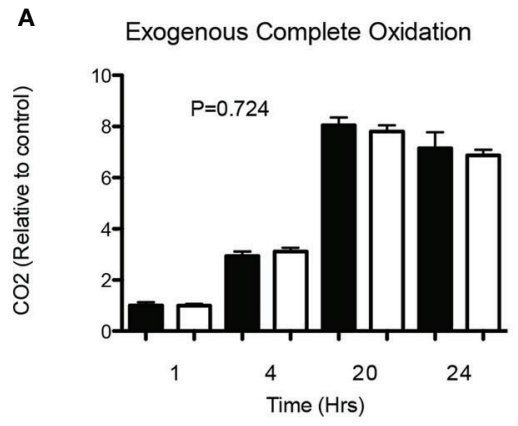

C Endogenous Complete Oxidation

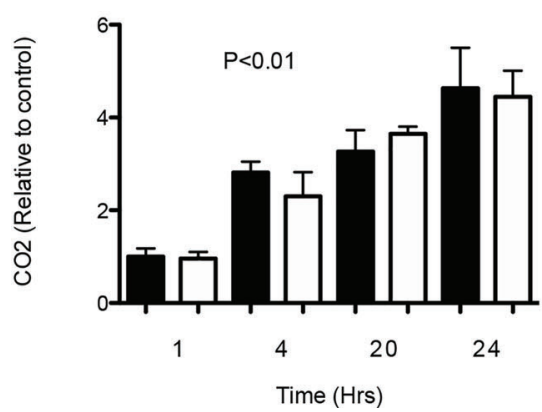

Exogenous Incomplete Oxidation

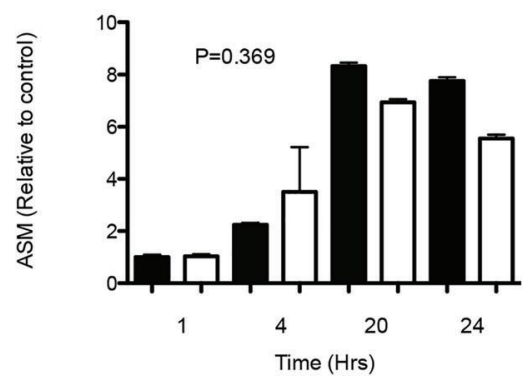

D

Endogenous Incomplete Oxidation

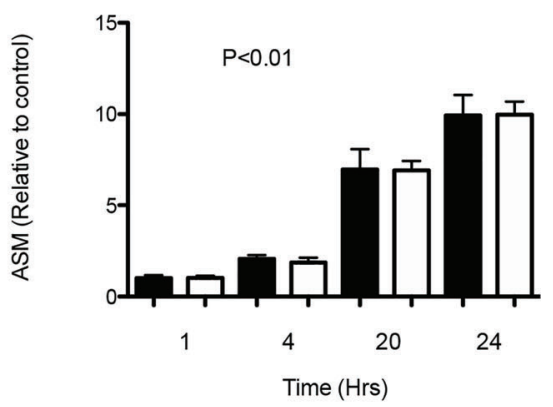

FIGURE 1 | Time-effect of SA on exogenous and endogenous fat oxidation in HSkMC. (A) Complete $\left({ }^{14} \mathrm{CO}_{2}\right)$ and (B) incomplete (ASM) ${ }^{14} \mathrm{C}$-palmitate exogenous oxidation (2 independent experiments) was measured following 1, 4, 20 and 24 hours of incubation without (0 mmo//) or with (0.1 mmol//) SA. In addition, following 24h pre-incubation with ${ }^{14} \mathrm{C}$-palmitate, (C) complete $\left({ }^{14} \mathrm{CO}_{2}\right)$ and (D) incomplete (ASM) ${ }^{14} \mathrm{C}$-palmitate endogenous oxidation (2 independent experiments) was measured following 1, 4, 20- and 24-hours incubation without $(0 \mathrm{mmo} / \mathrm{l})$ or with $(0.1 \mathrm{mmo} / \mathrm{l}) \mathrm{SA}$. Data expressed as mean and standard deviation and expressed as relative to control (black). P value corresponds to Kruskal-Wallis test. Post-hoc test showed no differences between control and acetate treated cells at each timepoint.

\section{Effect of SA on AMPK Phosphorylation}

In line with our oxidation data, we did not observe a time ( $2 \mathrm{~min}$, $10 \mathrm{~min}$, and $24 \mathrm{~h})$ or dose $(0.1$ and $0.5 \mathrm{mmol} / \mathrm{L})$ dependent effect on total or phosphorylated $T h r^{172}-A M P K \alpha$ content in HSkMC (Figure 3). Of interest, $T h r^{172}-A M P K \alpha$ phosphorylation was increased in our HSkMC model following 4- and 6-h incubations with the major AMPK activator AICAR ( $1 \mathrm{mmol} / \mathrm{L})$ (Figure S3). Nevertheless, this AICAR-mediated increase in AMPK phosphorylation was not accompanied by an increased complete nor incomplete exogenous/endogenous fat oxidation using AICAR (1 mmol/L) (Figure S2). In contrast, treatment of HSkMC using an inhibitor (etomoxir, $100 \mu \mathrm{mol} / \mathrm{L}$ ) showed marked changes in complete and incomplete palmitate oxidation, indicating that our HSkMC is dynamic and fully functional (Figure S2).

\section{DISCUSSION}

Recently we showed that distal (not proximal) colonic infusions of acetate and SCFA mixtures (rich in acetate) increased circulating acetate levels $(120 \mathrm{~min})$ in overweight/obese humans $(7,37)$. Of note, we found a positive relationship between increments in acetate levels and fasting whole-body fat oxidation. Therefore, we hypothesized that circulating acetate may directly affect fat oxidation in human skeletal muscle contributing to the observed increments in in vivo whole-body fat oxidation. To our knowledge, this is the first study that investigates the direct (dose/time) effects of SA on fat oxidation (endo-exogenous) and whether effects are dependent on AMPK phosphorylation in a HSkMC model. However, our data showed no time- or dose-dependent increase of SA on either endo- or exogenous palmitate oxidation in HSkMC. In line, AMPK phosphorylation was not affected by acute nor chronic SA treatment.

In vivo colonic infusions $(37,38)$ showed an acute effect on fasting whole-body fat oxidation in overweight-obese men with acetate concentrations reaching average plasma acetate levels of 40 $\mu \mathrm{mol} / \mathrm{L}$. However, our in vitro experiments showed no dose- or time effect of SA, with physiological concentrations $(0-0.5 \mathrm{mmol} /$ L), reached after in vivo dietary fiber fermentation (10-13), and no effect with supraphysiological concentrations (1-5 mmol/L). Although the actual interstitial/intracellular concentration of acetate in the skeletal muscle remains unknown, it has been suggested in rats (39) and humans (40) that acetate uptake in skeletal muscle is proportional to circulating levels. In support, using labeled ${ }^{13} \mathrm{C}$ SA in healthy lean individuals has shown ${ }^{13} \mathrm{CO}_{2}$ breath recovery rates between $40-80 \%$, which may indicate acetate uptake and utilization/oxidation in the TCA cycle of metabolically 
A

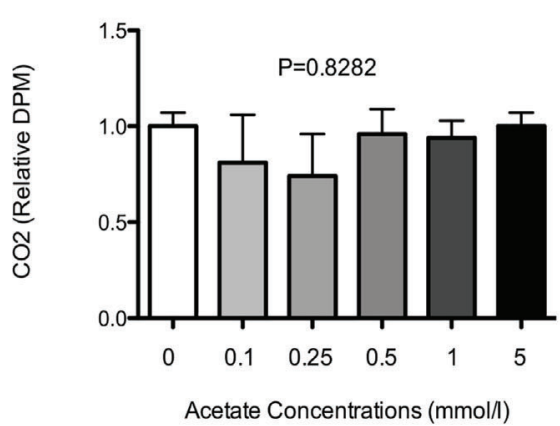

C

Endogenous Complete Oxidation

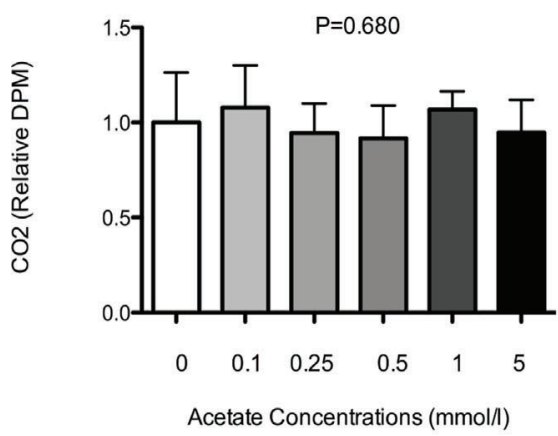

B

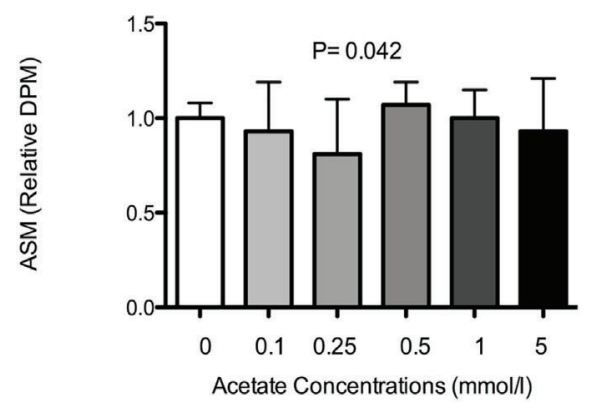

D

Endogenous Incomplete Oxidation

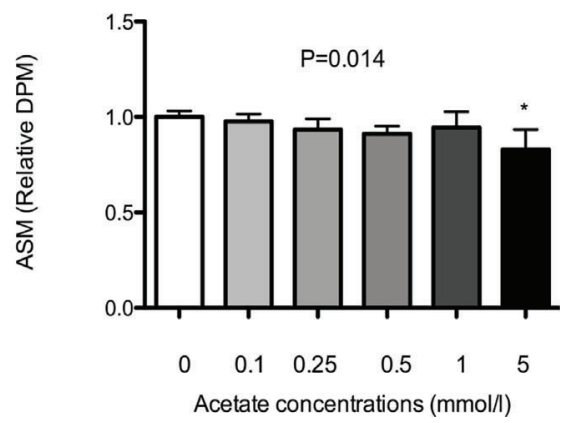

FIGURE 2 | Dose-effect of SA on exogenous and endogenous fat oxidation in HSkMC. (A) Complete $\left({ }^{14} \mathrm{CO}_{2}\right)$ and (B) incomplete (ASM) ${ }^{14} \mathrm{C}$-palmitate exogenous oxidation (5 independent experiments) was measured following $20 \mathrm{~h}$ incubation without (0 mmol//) or with (0.1-5 mmol//) SA. In addition, following $24 \mathrm{~h}$ pre-incubation with ${ }^{14} \mathrm{C}$-palmitate, (C) complete $\left({ }^{14} \mathrm{CO}_{2}\right)$ and (D) incomplete (ASM) ${ }^{14} \mathrm{C}$-palmitate endogenous oxidation (4 independent experiments) was measured following $20 \mathrm{~h}$ incubation without $(0 \mathrm{mmol} / \mathrm{l})$ or with $(0.1-5 \mathrm{mmo} / /) \mathrm{SA}$. Data expressed as mean and standard deviation and expressed as relative to control treated cells. $\mathrm{P}$ value corresponds to Kruskal-Wallis test. Post-hoc test significance is compared to control $(0 \mathrm{mmol} / \mathrm{l})$ indicated as asterisk (*) when $\mathrm{P}<0.05$.

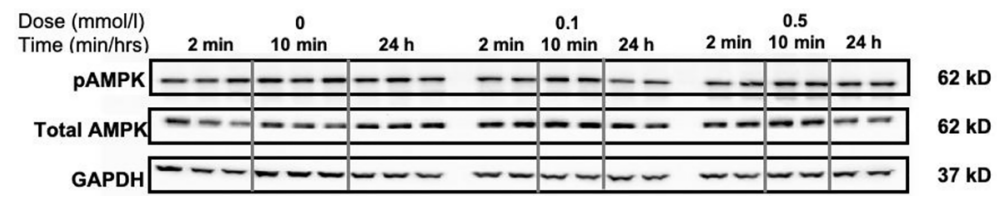

FIGURE 3 | Time and dose-dependent effects of SA on total and PAMPK in HSkMC. Cells were incubated without (0 mmol//) and with (0.1 and $0.5 \mathrm{mmol} / \mathrm{l}) \mathrm{SA}$ for 2 or $10 \mathrm{~min}$ and up to $24 \mathrm{~h}$. After incubation, cells were lysed with RIPA buffer supplemented with protease and phosphatase inhibitors and samples were subjected to western analysis for total AMPK $\alpha$ (62kD band), phosphorylated AMPK (Thr $\left.{ }^{172}-A M P K \alpha\right)$ and GAPDH (37kD band) was used as a loading control.

relevant organs (i.e. liver, muscle) (41-43). Of note, in our in vitro experiments SA was provided as a single bolus, and acetate may have been rapidly absorbed, and used into the tricarboxylic acid cycle (TCA) and saturate connecting metabolic pathways (44). In support, acute intravenous infusions of acetate $(2.5 \mathrm{mmol}$ per $\mathrm{min}$ for $1 \mathrm{~h}$ ) in humans did not increase energy expenditure, which was partly explained by the fact that acetate might replace long chain fatty acids as preferred oxidation fuel in TCA-connected metabolic pathways (45). Of interest, a slight time-dependent decrease in endogenous (incomplete) oxidation was observed (Figure 2D), which reached significance following incubation with the highest dose of SA (5 mmol/L) compared to control cells, possibly indicating preferential use of SA as oxidation fuel. Future studies using labeled SA are needed in order to investigate the metabolic fate of acetate in human skeletal muscle. Moreover, whether metabolic effects of acetate in human skeletal muscle are 
GPR-dependent remains unclear given the inconclusive expression of GPR 41 in our HSkMC model (Figure S5) and therefore warrant further investigation of other GPRs (e.g. GPR43).

As mentioned above, our design (one single bolus of SA), may not mimic a continuous delivery of gut-derived acetate to the skeletal muscle. Acetate colonic absorption seems to be concentration dependent (46) and to gradually increase plasma levels, thus reaching skeletal muscle in a more continuous manner in vivo. Nevertheless, our doses were based on human prebiotic interventions that report circulating acetate concentrations up to $450 \mu \mathrm{mol} / \mathrm{L}$ (9-14). In support of a continuous supply, a 4-week supplementation of a high amount of fermentable (type 2) resistant starch $(30 \mathrm{~g} / \mathrm{d} v s$ rapidly digestible starch $20 \mathrm{~g}$ ) increased acetate uptake in skeletal muscle (and adipose tissue) in healthy subjects (47). Although no fat oxidation was measured, the intervention improved peripheral insulin sensitivity (euglycemic hyperinsulinemic clamp) (47), thus potentially indicating that a continuous supply of gut-derived acetate into the muscle (instead of a single bolus) is needed to induce major metabolic effects.

Based on previous animal data, acetate (oral injection) acutely increases phosphorylation of $T h r^{172}-A M P K \alpha$, at least in rat skeletal muscle (in vivo) and in vitro using L6 myotubes (30, 31). The putative mechanism of acetate in the regulation of skeletal muscle fat oxidation, is through rapid (acute) catabolic conversion of acetate to acetyl CoA (mediated by acetyl Co A synthase), increasing the AMP/ATP ratio which subsequently increases AMPK phosphorylation. We replicated the exact same incubation time/dose as in above mentioned animal studies; however, we could not corroborate previous results. Importantly, our model is fully functional as observed by pronounced effects of Etomoxir.

Nevertheless, our model may not be the ideal system to investigate (acute) AMPK-dependent effects on fat oxidation (See Figure S2) and/or effects may be donor-specific $(48,49)$. Of note, AICAR administration in humans did not increase AMPK phosphorylation in skeletal muscle but increased hepatic fatty acid oxidation and lowered hepatic glucose production (50). Furthermore, AMPK-dependent fat oxidation might be limited in HSkMC and/or an AMPK-dependent effect on glucose uptake/oxidation may be preferentially activated $(51,52)$ as well as muscle fiber type-dependent activation of AMPK (53) in HSkMC. Although, acetate has shown AMPK-dependent fat oxidation in rodents, acetate-mediated effect on AMPK activation in skeletal muscle may be species-specific (54).

Lastly, circulating acetate may modulate other metabolically active tissues in humans that may explain the in vivo increments in whole-body fat oxidation. First, SA may increase liver/adipose tissue fat oxidative capacity, since in vitro and rodent studies have shown increments in phosphorylated AMPK and total AMPK $(31,32)$. In addition, acetate turnover rate is the highest in the liver of mammals as compared to other tissues (i.e. muscle and adipose tissues) indicating an important regulatory role of the liver in acetate metabolism (55). Second, other gut-derived metabolites such as butyrate may increase mitochondrial function and expression of fatty acid oxidative genes as observed in mice skeletal muscle $(56,57)$. Kinetic studies demonstrated that around $24 \%$ of colonic acetate is converted via bacterial cross-feeding into butyrate in metabolically healthy adults (58).

Finally, SCFA might affect the secretion of gut-derived hormones such as PYY and GLP-1, which have been associated with increased whole-body fat oxidation and energy expenditure in humans $(59,60)$. In line, data from our group and others reported increments of circulating PYY levels following colonic SCFA infusion in humans $(37,61)$. In agreement, a recent study reported that human skeletal muscle and muscle progenitor cells express PYY and its receptors, suggesting that our observed increase in whole-body fat oxidation might be partly explained via PYY-mediated effects on muscle fat oxidation (62). Our model showed no expression of the PYY receptor NPY2R during proliferation and differentiation (data not shown).

In addition, other gut-derived peptides warrant further investigation with respect to their respective roles on skeletal muscle fat oxidation under different metabolic status. For instance, ghrelin and gastric inhibitory polypeptide (GIP) may affect fat oxidation and thereby a protective role in lipid-induced skeletal muscle insulin resistance $(63,64)$. Moreover, fibroblast growth factor (FGF) 15/19 secreted from small intestine should be further investigated regarding their involvement in human skeletal muscle fat oxidation (65).

In conclusion, our data showed no time- or dose-dependent increase of SA on endogenous or exogenous palmitate oxidation as well as no increments in AMPK phosphorylation following acute/chronic SA treatment in our human primary muscle cell model HSkMC derived from a lean insulin sensitive male donor. However, we cannot exclude that our previously reported in vivo effect of colonic acetate administration on fat oxidation in overweight individuals might be partly explained by the effect of other gut-derived metabolites and their signaling pathways (i.e. via PYY) on muscle fat oxidation or by direct effects of SCFA (i.e. butyrate) on other tissues (i.e. liver and adipose tissue). Furthermore, fat oxidation might be donor-dependent and/or species-specific.

\section{DATA AVAILABILITY STATEMENT}

The raw data supporting the conclusions of this article will be made available by the authors, without undue reservation.

\section{ETHICS STATEMENT}

The studies involving human participants were reviewed and approved by Medical Ethical Committee Jessa Hospital, Hasselt, and Hasselt University, Belgium. The patients/participants provided their written informed consent to participate in this study. 


\section{AUTHOR CONTRIBUTIONS}

MG, JJ, EC, and EB were responsible for the study concept and design, analysis and interpretation of the data, and critical revision of the manuscript for important intellectual content. MG, YE, and NH generated data. MG acquired all data, completed statistical analysis, and drafted the manuscript. EB obtained funding and supervised the study. All authors contributed to the article and approved the submitted version.

\section{FUNDING}

The study was supported by a Kootstra Talent grant from Maastricht University Medical Centre ${ }^{+}$(Applicant: EB, Candidate: EC) and MG's salary was paid by a grant from

\section{REFERENCES}

1. Engin A. The Definition and Prevalence of Obesity and Metabolic Syndrome. Adv Exp Med Biol (2017) 960:1-17. doi: 10.1007/978-3-319-48382-5_1

2. Stinkens R, Goossens GH, Jocken JW, Blaak EE. Targeting Fatty Acid Metabolism to Improve Glucose Metabolism. Obes Rev Off J Int Assoc Study Obes (2015) 16(9):715-57. doi: 10.1111/obr.12298

3. Canfora EE, Jocken JW, Blaak EE. Short-Chain Fatty Acids in Control of Body Weight and Insulin Sensitivity. Nat Rev Endocrinol (2015) 11(10):577-91. doi: 10.1038/nrendo.2015.128

4. Canfora EE, Meex RCR, Venema K, Blaak EE. Gut Microbial Metabolites in Obesity, NAFLD and T2DM. Nat Rev Endocrinol (2019) 15(5):261-73. doi: 10.1038/s41574-019-0156-Z

5. Conlon MA, Bird AR. The Impact of Diet and Lifestyle on Gut Microbiota and Human Health. Nutrients (2015) 7(1):17-44. doi: 10.3390/nu7010017

6. Marchesi JR, Adams DH, Fava F, Hermes GDA, Hirschfield GM, Hold G, et al. The Gut Microbiota and Host Health: A New Clinical Frontier. Gut (2015) 65(2):330-9. doi: 10.1136/gutjnl-2015-309990

7. Canfora EE, Blaak EE. Acetate: A Diet-Derived Key Metabolite in Energy Metabolism: Good or Bad in Context of Obesity and Glucose Homeostasis? Curr Opin Clin Nutr Metab Care (2017) 20(6):477-3. doi: 10.1097/ MCO.0000000000000408

8. Cummings JH, Pomare EW, Branch WJ, Naylor CP, Macfarlane GT. Short Chain Fatty Acids in Human Large Intestine, Portal, Hepatic and Venous Blood. Gut (1987) 28(10):1221-7. doi: 10.1136/gut.28.10.1221

9. Müller M, Hernández MAG, Goossens GH, Reijnders D, Holst JJ, Jocken JWE, et al. Circulating But Not Faecal Short-Chain Fatty Acids Are Related to Insulin Sensitivity, Lipolysis and GLP-1 Concentrations in Humans. Sci Rep (2019) 9(1):12515. doi: 10.1038/s41598-019-48775-0

10. Ferchaud-Roucher V, Pouteau E, Piloquet H, Zair Y, Krempf M. Colonic Fermentation From Lactulose Inhibits Lipolysis in Overweight Subjects. Am J Physiol Endocrinol Metab (2005) 289(4):E716-20. doi: 10.1152/ ajpendo.00430.2004

11. Pouteau E, Vahedi K, Messing B, Flourie B, Nguyen P, Darmaun D, et al. Production Rate of Acetate During Colonic Fermentation of Lactulose: A Stable-Isotope Study in Humans. Am J Clin Nutr (1998) 68(6):1276-83. doi: 10.1093/ajcn/68.6.1276

12. Luo J, Rizkalla SW, Alamowitch C, Boussairi A, Blayo A, Barry JL, et al. Chronic Consumption of Short-Chain Fructooligosaccharides by Healthy Subjects Decreased Basal Hepatic Glucose Production But Had No Effect on Insulin-Stimulated Glucose Metabolism. Am J Clin Nutr (1996) 63(6):939-45. doi: 10.1093/ajcn/63.6.939

13. Boll EV, Ekstrom LM, Courtin CM, Delcour JA, Nilsson AC, Bjorck IM, et al. Effects of Wheat Bran Extract Rich in Arabinoxylan Oligosaccharides and Resistant Starch on Overnight Glucose Tolerance and Markers of Gut
Consejo Nacional de Ciencia y Tecnología (CONACYT). The funders had no role in study design, data collection and analysis, decision to publish, or preparation of the manuscript.

\section{ACKNOWLEDGMENTS}

We are thankful for all volunteers that participate in our studies.

\section{SUPPLEMENTARY MATERIAL}

The Supplementary Material for this article can be found online at: https://www.frontiersin.org/articles/10.3389/fendo.2021. 659928/full\#supplementary-material

Fermentation in Healthy Young Adults. Eur J Nutr (2016) 55(4):1661-70. doi: 10.1007/s00394-015-0985-z

14. Canfora EE, van der Beek CM, Hermes GDA, Goossens GH, Jocken JWE, Holst JJ, et al. Supplementation of Diet With Galacto-Oligosaccharides Increases Bifidobacteria, But Not Insulin Sensitivity, in Obese Prediabetic Individuals. Gastroenterology (2017) 153(1):87-97.e3. doi: 10.1053/ j.gastro.2017.03.051

15. Neis EPJG, van Eijk HMH, Lenaerts K, Olde Damink SWM, Blaak EE, Dejong CHC, et al. Distal Versus Proximal Intestinal Short-Chain Fatty Acid Release in Man. Gut (2019) 68(4):764. doi: 10.1136/gutjnl-2018-316161

16. Le Poul E, Loison C, Struyf S, Springael JY, Lannoy V, Decobecq ME, et al. Functional Characterization of Human Receptors for Short Chain Fatty Acids and Their Role in Polymorphonuclear Cell Activation. J Biol Chem (2003) 278 (28):25481-9. doi: 10.1074/jbc.M301403200

17. Brown AJ, Goldsworthy SM, Barnes AA, Eilert MM, Tcheang L, Daniels D, et al. The Orphan G Protein-Coupled Receptors GPR41 and GPR43 Are Activated by Propionate and Other Short Chain Carboxylic Acids. J Biol Chem (2003) 278(13):11312-9. doi: 10.1074/jbc.M211609200

18. Tang C, Ahmed K, Gille A, Lu S, Grone H-J, Tunaru S, et al. Loss of FFA2 and FFA3 Increases Insulin Secretion and Improves Glucose Tolerance in Type 2 Diabetes. Nat Med (2015) 21(2):173-7. doi: 10.1038/nm.3779

19. Priyadarshini M, Villa SR, Fuller M, Wicksteed B, Mackay CR, Alquier T, et al. Ffar2, Regulates Insulin Secretion. Mol Endocrinol (2015) 29(7):1055-66. doi: 10.1210/me.2015-1007

20. Ge H, Li X, Weiszmann J, Wang P, Baribault H, Chen J-L, et al. Activation of G Protein-Coupled Receptor 43 in Adipocytes Leads to Inhibition of Lipolysis and Suppression of Plasma Free Fatty Acids. Endocrinology (2008) 149 (9):4519-26. doi: 10.1210/en.2008-0059

21. Aberdein N, Schweizer M, Ball D. Sodium Acetate Decreases Phosphorylation of Hormone Sensitive Lipase in Isoproterenol-Stimulated 3T3-L1 Mature Adipocytes. Adipocyte (2014) 3(2):121-5. doi: 10.4161/adip.27936

22. Jocken JWE, González Hernández MA, Hoebers NTH, van der Beek CM, Essers YPG, Blaak EE, et al. Short-Chain Fatty Acids Differentially Affect Intracellular Lipolysis in a Human White Adipocyte Model. Front Endocrinol (2018) 8(372). doi: 10.3389/fendo.2017.00372

23. Sahuri-Arisoylu M, Brody LP, Parkinson JR, Parkes H, Navaratnam N, Miller $\mathrm{AD}$, et al. Reprogramming of Hepatic Fat Accumulation and 'Browning' of Adipose Tissue by the Short-Chain Fatty Acid Acetate. Int J Obes (2005) (2016) 40(6):955-63. doi: 10.1038/ijo.2016.23

24. Crouse JR, Gerson CD, DeCarli LM, Lieber CS. Role of Acetate in the Reduction of Plasma Free Fatty Acids Produced by Ethanol in Man. J Lipid Res (1968) 9(4):509-12. doi: 10.1016/S0022-2275(20)42731-2

25. Laurent C, Simoneau C, Marks L, Braschi S, Champ M, Charbonnel B, et al. Effect of Acetate and Propionate on Fasting Hepatic Glucose Production in Humans. Eur J Clin Nutr (1995) 49(7):484-91. 
26. Wolever TM, Brighenti F, Royall D, Jenkins AL, Jenkins DJ. Effect of Rectal Infusion of Short Chain Fatty Acids in Human Subjects. Am J Gastroenterol (1989) 84(9):1027-33.

27. Suokas A, Kupari M, Heikkila J, Lindros K, Ylikahri R. Acute Cardiovascular and Metabolic Effects of Acetate in Men. Alcohol Clin Exp Res (1988) 12 (1):52-8. doi: 10.1111/j.1530-0277.1988.tb00132.x

28. Keenan MJ, Zhou J, McCutcheon KL, Raggio AM, Bateman HG, Todd E, et al. Effects of Resistant Starch, a Non-Digestible Fermentable Fiber, on Reducing Body Fat. Obes (Silver Spring Md) (2006) 14(9):1523-34. doi: 10.1038/ oby.2006.176

29. Cani PD, Dewever C, Delzenne NM. Inulin-Type Fructans Modulate Gastrointestinal Peptides Involved in Appetite Regulation (Glucagon-Like Peptide-1 and Ghrelin) in Rats. Br J Nutr (2004) 92(3):521-6. doi: 10.1079/ BJN20041225

30. Maruta H, Yoshimura Y, Araki A, Kimoto M, Takahashi Y, Yamashita H. Activation of AMP-Activated Protein Kinase and Stimulation of Energy Metabolism by Acetic Acid in L6 Myotube Cells. PloS One (2016) 11(6): e0158055. doi: 10.1371/journal.pone.0158055

31. Yamashita H, Maruta H, Jozuka M, Kimura R, Iwabuchi H, Yamato M, et al. Effects of Acetate on Lipid Metabolism in Muscles and Adipose Tissues of Type 2 Diabetic Otsuka Long-Evans Tokushima Fatty (OLETF) Rats. Biosci Biotechnol Biochem (2009) 73(3):570-6. doi: 10.1271/bbb.80634

32. Sakakibara S, Yamauchi T, Oshima Y, Tsukamoto Y, Kadowaki T. Acetic Acid Activates Hepatic AMPK and Reduces Hyperglycemia in Diabetic KK-A(y) Mice. Biochem Biophys Res Commun (2006) 344(2):597-604. doi: 10.1016/ j.bbrc.2006.03.176

33. Kondo T, Kishi M, Fushimi T, Kaga T. Acetic Acid Upregulates the Expression of Genes for Fatty Acid Oxidation Enzymes in Liver to Suppress Body Fat Accumulation. J Agric Food Chem (2009) 57(13):5982-6. doi: 10.1021/jf900470c

34. Smith PM, Howitt MR, Panikov N, Michaud M, Gallini CA, Bohlooly YM, et al. The Microbial Metabolites, Short-Chain Fatty Acids, Regulate Colonic Treg Cell Homeostasis. Sci (New York NY) (2013) 341(6145):569-73. doi: $10.1126 /$ science. 1241165

35. Verboven K, Wouters K, Gaens K, Hansen D, Bijnen M, Wetzels S, et al. Abdominal Subcutaneous and Visceral Adipocyte Size, Lipolysis and Inflammation Relate to Insulin Resistance in Male Obese Humans. Sci Rep (2018) 8(1):4677. doi: 10.1038/s41598-018-22962-x

36. Hulver MW, Berggren JR, Carper MJ, Miyazaki M, Ntambi JM, Hoffman EP, et al. Elevated Stearoyl-CoA Desaturase-1 Expression in Skeletal Muscle Contributes to Abnormal Fatty Acid Partitioning in Obese Humans. Cell Metab (2005) 2(4):251-61. doi: 10.1016/j.cmet.2005.09.002

37. van der Beek CM, Canfora EE, Lenaerts K, Troost FJ, Damink S, Holst JJ, et al. Distal, Not Proximal, Colonic Acetate Infusions Promote Fat Oxidation and Improve Metabolic Markers in Overweight/Obese Men. Clin Sci (Lond) (2016) 130(22):2073-82. doi: 10.1042/CS20160263

38. Canfora EE, van der Beek CM, Jocken JWE, Goossens GH, Holst JJ, Olde Damink SWM, et al. Colonic Infusions of Short-Chain Fatty Acid Mixtures Promote Energy Metabolism in Overweight/Obese Men: A Randomized Crossover Trial. Sci Rep (2017) 7(1):2360. doi: 10.1038/s41598-017-02546-x

39. Karlsson N, Fellenius E, Kiessling KH. The Metabolism of Acetate in the Perfused Hind-Quarter of the Rat. Acta Physiol Scand (1975) 93(3):391-400. doi: 10.1111/j.1748-1716.1975.tb05828.x

40. Skutches CL, Holroyde CP, Myers RN, Paul P, Reichard GA. Plasma Acetate Turnover and Oxidation. J Clin Invest (1979) 64(3):708-13. doi: 10.1172/JCI109513

41. Mittendorfer B, Sidossis LS, Walser E, Chinkes DL, Wolfe RR. Regional Acetate Kinetics and Oxidation in Human Volunteers. Am J Physiol Endocrinol Metab (1998) 274(6):E978-83. doi: 10.1152/ajpendo.1998.274.6.E978

42. Pouteau E, Piloquet H, Maugeais P, Champ M, Dumon H, Nguyen P, et al. Kinetic Aspects of Acetate Metabolism in Healthy Humans Using [1-13C] Acetate. Am J Physiol Endocrinol Metab (1996) 271(1):E58-64. doi: 10.1152/ ajpendo.1996.271.1.E58

43. Wolfe RR, Jahoor F. Recovery of Labeled CO2 During the Infusion of C-1- vs C-2-Labeled Acetate: Implications for Tracer Studies of Substrate Oxidation. Am J Clin Nutr (1990) 51(2):248-52. doi: 10.1093/ajcn/51.2.248

44. Neavyn MJ, Boyer EW, Bird SB, Babu KM. Sodium Acetate as a Replacement for Sodium Bicarbonate in Medical Toxicology: A Review. J Med Toxicol (2013) 9(3):250-4. doi: 10.1007/s13181-013-0304-0
45. Akanji AO, Bruce MA, Frayn KN. Effect of Acetate Infusion on Energy Expenditure and Substrate Oxidation Rates in Non-Diabetic and Diabetic Subjects. Eur J Clin Nutr (1989) 43(2):107-15.

46. Ruppin H, Bar-Meir S, Soergel KH, Wood CM, Schmitt MG Jr. Absorption of Short-Chain Fatty Acids by the Colon. Gastroenterology (1980) 78(6):1500-7. doi: 10.1016/S0016-5085(19)30508-6

47. Robertson MD, Bickerton AS, Dennis AL, Vidal H, Frayn KN. InsulinSensitizing Effects of Dietary Resistant Starch and Effects on Skeletal Muscle and Adipose Tissue Metabolism. Am J Clin Nutr (2005) 82(3):559-67. doi: 10.1093/ajcn/82.3.559

48. Bajpeyi S, Myrland CK, Covington JD, Obanda D, Cefalu WT, Smith SR, et al. Lipid in Skeletal Muscle Myotubes Is Associated to the Donors' Insulin Sensitivity and Physical Activity Phenotypes. Obes (Silver Spring Md) (2014) 22(2):426-34. doi: 10.1002/oby.20556

49. Ukropcova B, McNeil M, Sereda O, de Jonge L, Xie H, Bray GA, et al. Dynamic Changes in Fat Oxidation in Human Primary Myocytes Mirror Metabolic Characteristics of the Donor. J Clin Invest (2005) 115(7):1934-41. doi: 10.1172/JCI24332

50. Boon H, Bosselaar M, Praet SF, Blaak EE, Saris WH, Wagenmakers AJ, et al. Intravenous AICAR Administration Reduces Hepatic Glucose Output and Inhibits Whole Body Lipolysis in Type 2 Diabetic Patients. Diabetologia (2008) 51(10):1893-900. doi: 10.1007/s00125-008-1108-7

51. Sakoda H, Ogihara T, Anai M, Fujishiro M, Ono H, Onishi Y, et al. Activation of AMPK Is Essential for AICAR-Induced Glucose Uptake by Skeletal Muscle But Not Adipocytes. Am J Physiol Endocrinol Metab (2002) 282(6):E1239-44. doi: 10.1152/ajpendo.00455.2001

52. Musi N, Goodyear LJ. AMP-Activated Protein Kinase and Muscle Glucose Uptake. Acta Physiol Scand (2003) 178(4):337-45. doi: 10.1046/j.1365201X.2003.01168.x

53. Tobias IS, Lazauskas KK, Siu J, Costa PB, Coburn JW, Galpin AJ. Sex and Fiber Type Independently Influence AMPK, TBC1D1, and TBC1D4 at Rest and During Recovery From High-Intensity Exercise in Humans. J Appl Physiol (Bethesda Md 1985) (2020) 128(2):350-61. doi: 10.1152/japplphysiol. 00704.2019

54. Kjøbsted R, Hingst JR, Fentz J, Foretz M, Sanz M-N, Pehmøller C, et al. AMPK in Skeletal Muscle Function and Metabolism. FASEB J Off Publ Fed Am Soc Exp Biol (2018) 32(4):1741-77. doi: 10.1096/fj.201700442R

55. Knowles SE, Jarrett IG, Filsell OH, Ballard FJ. Production and Utilization of Acetate in Mammals. Biochem J (1974) 142(2):401-11. doi: 10.1042/ bj1420401

56. Hong J, Jia Y, Pan S, Jia L, Li H, Han Z, et al. Butyrate Alleviates High Fat Diet-Induced Obesity Through Activation of Adiponectin-Mediated Pathway and Stimulation of Mitochondrial Function in the Skeletal Muscle of Mice. Oncotarget (2016) 7(35):56071-82. doi: 10.18632/ oncotarget. 11267

57. Frampton J, Murphy K, Frost G, Chambers E. Short-Chain Fatty Acids as Potential Regulators of Skeletal Muscle Metabolism and Function. Nat Metab (2020) 2:840-8. doi: 10.1038/s42255-020-0188-7

58. Boets E, Gomand SV, Deroover L, Preston T, Vermeulen K, De Preter V, et al. Systemic Availability and Metabolism of Colonic-Derived Short-Chain Fatty Acids in Healthy Subjects: A Stable Isotope Study. J Physiol (2017) 595 (2):541-55. doi: 10.1113/JP272613

59. Pannacciulli N, Bunt JC, Koska J, Bogardus C, Krakoff J. Higher Fasting Plasma Concentrations of Glucagon-Like Peptide 1 Are Associated With Higher Resting Energy Expenditure and Fat Oxidation Rates in Humans. Am J Clin Nutr (2006) 84(3):556-60. doi: 10.1093/ajcn/84.3.556

60. Karra E, Chandarana K, Batterham RL. The Role of Peptide YY in Appetite Regulation and Obesity. J Physiol (2009) 587(1):19-25. doi: 10.1113/ jphysiol.2008.164269

61. Freeland KR, Wolever TMS. Acute Effects of Intravenous and Rectal Acetate on Glucagon-Like Peptide-1, Peptide YY, Ghrelin, Adiponectin and Tumour Necrosis Factor-Alpha. Br J Nutr (2010) 103(3):460-6. doi: 10.1017/ S0007114509991863

62. Gheller BJ, Blum JE, Merritt EK, Cummings BP, Thalacker-Mercer AE. Peptide YY (Pyy) Is Expressed in Human Skeletal Muscle Tissue and Expanding Human Muscle Progenitor Cells. Front Physiol (2019) 10:188. doi: $10.3389 /$ fphys.2019.00188 
63. Cervone DT, Hucik B, Lovell AJ, Dyck DJ. Unacylated Ghrelin Stimulates Fatty Acid Oxidation to Protect Skeletal Muscle Against Palmitate-Induced Impairment of Insulin Action in Lean But Not High-Fat Fed Rats. Metab Open (2020) 5:100026. doi: 10.1016/j.metop.2020.100026

64. Zhou H, Yamada Y, Tsukiyama K, Miyawaki K, Hosokawa M, Nagashima K, et al. Gastric Inhibitory Polypeptide Modulates Adiposity and Fat Oxidation Under Diminished Insulin Action. Biochem Biophys Res Commun (2005) 335 (3):937-42. doi: 10.1016/j.bbrc.2005.07.164

65. Guan D, Zhao L, Chen D, Yu B, Yu J. Regulation of Fibroblast Growth Factor 15/19 and 21 on Metabolism: In the Fed or Fasted State. J Trans Med (2016) 14 (1):63. doi: 10.1186/s12967-016-0821-0
Conflict of Interest: The authors declare that the research was conducted in the absence of any commercial or financial relationships that could be construed as a potential conflict of interest.

Copyright (๑) 2021 González Hernández, Blaak, Hoebers, Essers, Canfora and Jocken. This is an open-access article distributed under the terms of the Creative Commons Attribution License (CC BY). The use, distribution or reproduction in other forums is permitted, provided the original author(s) and the 'copyright owner(s) are credited and that the original publication in this journal is cited, in accordance with accepted academic practice. No use, distribution or reproduction is permitted which does not comply with these terms. 